\title{
QUANTITATIVE MEASUREMENT OF THE DEVELOPMENT OF RECRYSTALLIZATION TEXTURE IN OFE COPPER
}

\author{
C. T. NECKER ${ }^{1}$, R. D. DOHERTY ${ }^{1}$ and A. D. ROLLETT ${ }^{2}$ \\ 1 Department of Materials Engineering, \\ Drexel University, Philadelphia, PA 19104, USA \\ ${ }^{2}$ Mail Stop G770, Materials Science and Technology Division \\ Los Alamos National Laboratory, NM 87545, USA
}

\section{ABSTRACT}

High purity OFE copper samples, cold rolled 58,73 and $90 \%$, were studied at different fractions recrystallized to follow the change of texture, the associated kinetics, release of stored energy, growth rates and microstructures. Higher strains led to a stronger copper deformation component and a stronger cube recrystallization component. The strength of the cube texture correlated strongly with the frequency of cube nuclei at the early stage of recrystallization for the 73 and $90 \%$ reductions. The kinetics had low Avrami exponents of 1.1, 1.2 and 1.8 respectively for the 3 rolling reductions. Average growth rates, $G$, decreased linearly with fraction recrystallized. However, unlike the study by Hutchinson et al., here the rate of stored energy release was constant with fraction recrystallized.

\section{INTRODUCTION}

The structural transformation between deformation and recrystallization textures, DT and RT, has been widely investigated, particularly the development of the cube texture in cold rolled, recrystallized f.c.c. metals along with the disputed mechanisms of oriented nucleation and oriented growth ${ }^{(1,2)}$. The interest in the cube texture is both practical, for example the control of earing in aluminum beer cans, and theoretical, the development of theories for the prediction of recrystallization textures. Given the complexity of the deformed state and its structural instability on annealing, it is likely that the formation of strong RT will be understood only through an integrated study of all aspects of recrystallization. Recently, Hutchinson et al. ${ }^{(3)}$ and Ryde et al. ${ }^{(4)}$ combined many of these aspects, including texture, kinetics, growth rate, stored energy and microstructure, in their study of the effect of starting grain size on recrystallization of $93 \%$ cold rolled OFHC copper. The approach used in those studies $(3,4)$ has been adopted here. In this paper initial results on RT in cold rolled copper are reported as a function of rolling strain. In addition to the methods used previously $(3,4)$, the local Electron Backscatter Kikuchi Pattern, EBSP, technique ${ }^{(5)}$ has been used to study the correlation between the strength of the final cube texture and the nucleation frequency and size of near "cube" grains during recrystallization. So far only preliminary results of the EBSP technique have been obtained.

\section{EXPERIMENTAL PROCEDURE}

The oxygen-free electronic, OFE, copper has measurable impurities (greater than $1 \mathrm{ppm}$ ) of oxygen (10 ppm), iron (9 ppm), silver, tungsten and titanium ( $3 \mathrm{ppm}$ each), and zinc ( $2 \mathrm{ppm})$. The copper initially had a $50 \mu \mathrm{m}$ grain size and an almost random texture. It was cold rolled $58 \%$, 
$73 \%$ and $90 \%$ and samples were annealed in a silicone oil bath at $225^{\circ} \mathrm{C}, 200^{\circ} \mathrm{C}$ and $150^{\circ} \mathrm{C}$, respectively. Rolling plane surfaces were prepared by conventional metallographic techniques for texture analysis on a Scintag 5 Axis pole figure goniometer. The pole figures and orientation distributions, OD, were analyzed using the Los Alamos Preferred Orientation Package (popLA). The texture component strengths were evaluated based on the OD. Quantitative microscopy was performed on the longitudinal section containing the rolling plane normal and rolling directions. Ten photographs per sample were taken (at $400 \mathrm{x}$ ) in the backscatter mode to obtain channeling contrast on a CamScan Series 4 SEM and were analyzed (i) for the volume fraction recrystallized, $\mathrm{F}$, by image analysis and (ii) for the average growth rate of the recrystallized material, $\mathrm{G}=$ $(\mathrm{dF} / \mathrm{dt}) / \mathrm{S}$. $\mathrm{S}$ is area per unit volume of the interface between recrystallized and cold worked material measured by the linear intercept method ${ }^{(6)}$, as employed in Ryde et al. ${ }^{(4)}$. Samples were cut by electrical discharge machining and chemically thinned $25 \%$ for stored energy, E, measurements, using a Perkin-Elmer DSC 7 system at a heating rate of $20^{\circ} \mathrm{C} / \mathrm{min}$. Additional runs at $5,10,30$ and $40^{\circ} \mathrm{C} / \mathrm{min}$ were also performed to determine activation energies from onset temperatures. Residual values of $\mathrm{E}$ were measured for the $90 \%$ rolled material after partial isothermal recrystallization to determine the value of $\mathrm{dE} / \mathrm{dF}$. The local orientations were studied by EBSP using a Jeol 840 SEM equipped with a low level light camera and analysis system driven by Dingley software(5).

\section{RESULTS AND DISCUSSION}

The (111) recalculated pole figures for fully recrystallized samples after the 3 reductions are seen in Fig 1. The 58\% rolled copper shows no significant cube component and a weak retained rolling texture. The $73 \%$ material had a virtually random texture with some retained rolling texture in addition to a weak cube texture. A strong cube texture, with the twin of cube, was seen for the $90 \%$ cold rolled copper. The only surprising result here is that Ryde et al. ${ }^{(4)}$ found that their $50 \mu \mathrm{m}$ grain size copper cold rolled $93 \%$ had only a weak cube texture and retained rolling texture. This result conflicts with the extremely strong cube RT in our $90 \%$ cold rolled, $50 \mu \mathrm{m}$ grain size copper, Fig. 1c. The presence of the weak RT is attributed by Ryde et al. to the destruction of cube nuclei by shear banding as well as the presence of shear bands acting as heterogeneous nucleation sites. This is a reasonable deduction since our $90 \%$ rolled copper was stongly cube textured and did not shear band. Our RT is similar to Ryde et al.'s $15 \mu \mathrm{m}$ grain size copper which did not exhibit shear banding.

The DTs are similar for each rolling reduction, differing only in the strength of the deformation components. The results are given below as multiples of a random intensity from the OD. The deformation texture component strengths for the three rolling reductions are:

\begin{tabular}{lccccc} 
Rolling Reduction & Brass & Copper & Goss & \multicolumn{1}{c}{$\frac{\text { Cube }}{2.6}$} & $\frac{1}{0.6}$ \\
$58 \%$ & 3.6 & 2.6 & 1.1 & 1.4 & 1.1 \\
$73 \%$ & 2.8 & 3.0 & 0.9 & 1.1 & 1.3 \\
$90 \%$ & 0.7 & 5.7 & 0.1 & 0.7 &
\end{tabular}

After the samples were fully recrystallized, the following was seen:

\begin{tabular}{|c|c|c|c|c|c|}
\hline Rolling Reduction & Brass & Copper & Goss & $\underline{\mathbf{S}}$ & Cube \\
\hline $58 \%$ & 2.1 & 1.4 & $\overline{1.0}$ & $\overline{1.3}$ & $\overline{1.2}$ \\
\hline $73 \%$ & 1.8 & 1.5 & 1.3 & 1.4 & 2.1 \\
\hline $90 \%$ & 0.2 & 0.8 & 0.2 & 0.4 & 20.0 \\
\hline
\end{tabular}

Fig. 2 shows the change in the copper $(\mathrm{Cu})$ and cube components with fraction recrystallized, $\mathrm{F}$. The cube in the $90 \%$ rolled copper exhibits a dramatic non-linear increase while growing from 1.3 to 20 times random. The $\mathrm{Cu}$ strength was found to fall linearly with $\mathrm{F}$ for all 3 reductions. In 
the $58 \%$ and $73 \%$ rolled material the brass fell rapidly during the first $5 \%$ recrystallization but then fell only slighlty during the remaining recrystallization. Hutchinson ${ }^{(7)}$ and Virnich et al. ${ }^{(8)}$ have also reported that the $\mathrm{Cu}$ and near $\mathrm{Cu}$ orientations showed marked decreases in strength with increasing strength of cube. Also notable is that the strong increase of cube with strain in the RT is correlated, though non-linearly, with the increase in the weak cube component in the DT.

The EBSP results, though limited in extent, give striking support for a very strong correlation between the frequency of cube grains at the start of recrystallization and the cube strength in the RT at $100 \%$ transformation. Analysis of four recrystallized regions of a $73 \%$ rolled sample, recrystallized 6\%, found only 8 of 86 new grains were close to cube. Fig 3a shows the results on a $\{111\}$ pole figure. In the $90 \%$ rolled sample, that was $2 \%$ recrystallized, five recrystallized regions were analyzed. The 46 measurements from new grains gave 29 cube, 12 primary twins of cube, 3 secondary twins and 1 other non-cube orientation, see Fig. $3 \mathrm{~b}$. The cube and cube twin measurements are from 5 regions that are continuously twinned new grains with aspect ratios up to 25-30. There are small orientation differences in these regions but at present it is not clear how many of these regions are true separate nucleation events - presumably from a band of cube oriented sub-grains. TEM studies are likely to be needed to resolve such questions. The almost total lack of nuclei other than cube or cube related in the $90 \%$ rolled copper and the correlation between final recrystallization textures and EBSP results provide strong, but so far only qualitative, support for an oriented nucleation mechanism for RT. However the one cube nucleus whose location was photographically recorded in the $73 \%$ rolled sample was larger than the noncube regions, $50 \times 120 \mu \mathrm{m}$, against other new grains that were only about $20 \times 30 \mu \mathrm{m}$ in size. The recrystallized non-cube regions exhibit clustered grains. The size advantage may be due to: 1) nucleation of cube grains at earlier times than other orientations; 2) growth advantage of cube oriented nuclei; or 3) clustering of non-cube grains leading to earlier impingement. Further study by EBSP will be essential to determine, as recrystallization occurs, the correlation of relative cube grain size and frequency with overall RT development.

The recrystallization kinetics show classic sigmoidal curves. The $\mathbf{n}$ exponent values from Avrami plots $\left(\mathrm{F}=1-\exp -\left(\mathrm{kt}^{\mathrm{n}}\right)\right)$ are 1.1 for the $58 \%$ rolled copper, 1.2 for the $73 \%$ rolled and 1.8 for the $90 \%$ rolled copper, calculated from data that lie between $20 \%$ and $80 \%$ of full recrystallization. Deviations from linear Avrami plots $(\log \ln (1 / 1-F)$ vs. $\log t)$ were found at both the lowest and highest fractions recrystallized. The $\mathbf{n}$ values seen are those commonly found in recrystallization $(2,3,9,10)$ but are much smaller than those expected from the usual analysis with the expected constant growth rate in 3 dimensions where $n$ should be 3 to 4 . Failure of the simple analysis is predicted if the stored energy is not uniform which can lead to both clustering of nuclei and a fall in growth rate, $G$, with fraction recrystallized, $F$. A fall of $G$ with $F$ may also occur if significant recovery, lowering the residual stored energy, occurs during recrystallization ${ }^{(11-}$ 13).

Fig. 4 shows that the mean growth rate, G, actually showed a linear decrease with $F$ towards $G=0$, as $F \rightarrow 1$. Very similar results previously found by Ryde et al.(4) are also shown in Fig. 4. This observed fall in G, qualitatively at least, accounts for the low $\mathbf{n}$ values seen in both studies. What remains to be understood is the reason for this fall in G. Given the high purity of the copper, a possible hypothesis for the fall in $\mathrm{G}$ might be an increasing acquisition of solute by the migrating grain boundaries. The models of solute drag $(13,14)$ deal only with steady state migration and do not deal with a transient, solute acquisition, period. This idea is supported by two current observations: Firstly the increase in activation energy for the $90 \%$ rolled material as $\mathrm{F}$ increases, 111,135 and $160 \mathrm{~kJ} / \mathrm{g}$.mole at $\mathrm{F}=0,0.45$ and 0.7 . Secondly the maximum size of recrystallized grain clusters did not increase very much beyond the first $20 \%$ recrystallization though this currently qualitative observation needs further quantitative evaluation. Compte and Form ${ }^{(10)}$ reported similar observations in their study of copper recrystallization but came to the conclusion that solute accumulation was not the major reason for the reduction of $G$. An alternative model for the fall in $\mathrm{G}$ would be a change in the crystallography of the migrating grain boundaries. This hypthesis will require detailed EBSP studies on the partially recrystallized samples for testing. 
Hutchinson et al. ${ }^{(3)}$, by the elegant technique of observing the loss of residual stored energy, $\mathrm{E}$, with $\mathrm{F}$ in isothermal transformation, found that the loss was highly non linear: $\mathrm{dE} / \mathrm{dF}$ decreased monotonically as $\mathrm{F}$ increased for both coarse and fine grain sizes. The major surprise of the present study is shown in Fig. 5 where a linear decrease of $E$ with $F$ was found, $\mathrm{dE} / \mathrm{dF}$ is independent of $\mathrm{F}$, for the $90 \%$ rolled copper. This result rules out a recovery hypothesis and requires that if, as expected ${ }^{(2)}$, the stored energy varies for different starting orientations, then the spatial scale of this variation is smaller than the size of the recrystallized grains. In the $90 \%$ material the new grains grow to an average thickness of about $50 \mu \mathrm{m}, 10$ times the as rolled grain thickness. Therefore, E may be released homogeneously even if it was stored inhomogeneously. The origin of the difference with the previous work ${ }^{(3)}$ is not understood but may be affected by the shear bands seen by Ryde et al. ${ }^{(4)}$ but not here.

The much higher growth rates seen in the present work may be noted, Fig. 4. Normalized to $225^{\circ} \mathrm{C}$, using the measured activation energies from $\mathrm{E}$ measurements, and at $50 \%$ recrystallization, the recrystallized regions of $90 \%$ rolled copper grew $1.5 \mu \mathrm{m} / \mathrm{sec}$. This is 250 times faster than the 93\% rolled, coarse grain copper and 8 times faster than the fine grain copper ${ }^{(4)}$. This much faster growth is occurring even though the total $\mathrm{E}$ values after deformation are almost the same: $0.82 \mathrm{~J} / \mathrm{g}$ for our copper, $0.78 \mathrm{~J} / \mathrm{g}$ for the $93 \%$ rolled coarse grain copper ${ }^{(3)}$. An obvious possibility to explain this difference in $\mathbf{G}$ could be the higher purity of the copper used here which should give a lower solute drag $(13,14)$. The impingement of clustered grains nucleating on the shear bands also could be an explanation for the difference in $\mathrm{G}$.

\section{CONCLUSIONS}

The strength of cube RT in rolled copper was found to increase with rolling reduction. This increase was non-linearly correlated with a small increase in the cube texture in the deformed material and strongly correlated with the frequency of cube nuclei present in the early stages of recrystallization after 73 and $90 \%$ reduction. The low Avrami exponents found correlate with an observed linear fall in the mean growth rate as recrystallization progressed. Unlike the early study of Hutchinson et al. ${ }^{(3)}$, a constant rate of energy release with fraction recrystallized, $\mathrm{dE} / \mathrm{dF}$, was found here. The activation energy for recrystallization increased as $F$ increased. These initial studies need to be continued to give more detailed information and to give quantitative tests of the limited data available to date.

\section{ACKNOWLEDGEMENTS}

The authors gratefully acknowledge Los Alamos National Laboratory, Los Alamos, New Mexico, for financial support and ALCOA Technical Center, Pittsburgh, Pennsylvania, for the use of their EBSP facilities. We thank Dr. U. Kocks, Dr. R. Schwarz (Los Alamos) and Dr. J. Liu (ALCOA) for their useful discussions and advice.

\section{REFERENCES}

1. R.D. Doherty, G. Gottstein, J. Hirsch, W.B. Hutchinson, K. Lücke, E. Nes and P.J. Wilbrandt, "Report of Panel on Recrystallization Textures: Mechanisms and Experiments", Proceedings ICOTOM-8, 563 (1988).

2. A.D. Rollett, D.J. Srolovitz, R.D. Doherty and M.P. Anderson, Acta Metal., 37, 627 (1989).

3. W.B. Hutchinson, S. Jonsson and L. Ryde, Scripta Metall., 23, 671 (1989).

4. L. Ryde, W.B. Hutchinson and S. Jonsson, to be published in Recrystallization '90, AIME. 
5. R.T. DeHoff and F.N. Rhines, Quantitative Microscopy, Chapter 10 (McGraw-Hill, Inc., New York 1968).

6. D.J. Dingley, "On Line Microtexture Determination Using Backscatter Kikuchi Diffraction In A Scanning Electron Microscope", Proceedings ICOTOM-8, 189 (1988).

7. W.B. Hutchinson, Metal Sci., 8, 185 (1974).

8. K.H. Virnich, G. Köhloff, K. Lücke and J. Pospiech, "Texture Transformation During Primary Recrystallization of Rolled Copper Sheets as a Function of Annealing Time", Proceedings ICOTOM-7, 475 (1986).

9. T. Leffers "Modelling of Recrystallization Kinetics on Stereological Basis", Proceedings 7th Riso Conference, 427 (1986).

10. P.A. Compte and W. Form, Z. Metallk., 67, 158 (1976).

11. R.A.Vandermeer and P.Gordon in "Recovery and Recrystallization of Metals" Ed. L.Himmel, AIME, 211 (1962).

12. C.W. Price, Acta Metall., 38, 727 (1990).

13. J.W. Cahn, Acta Metall., 10, 789 (1962).

14. K. Lücke and H.P. Stüwe, in "Recovery and Recrystallization of Metals" Ed. L.Himmel, AIME, 171 (1962).

$$
\begin{gathered}
\text { random }=1.00 \\
2.00 \\
1.68 \\
1.41 \\
1.19 \\
1.00 \\
0.84 \\
0.71 \\
0.59 \\
0.50
\end{gathered}
$$

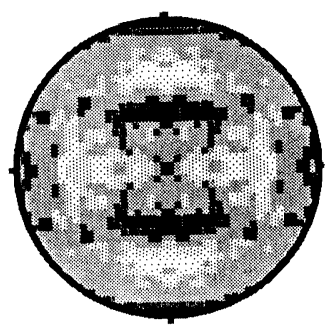

a)

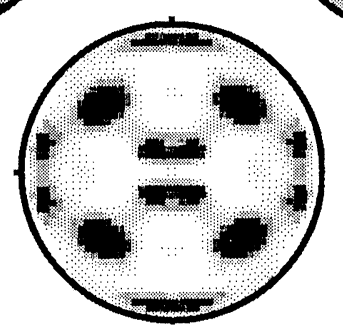

c)

Figure 1. Recalculated (111\} Pole Figure Quadrants for Fully Recrystallized Copper a) 58\% rolled, b) $73 \%$ rolled and c) $90 \%$ rolled.

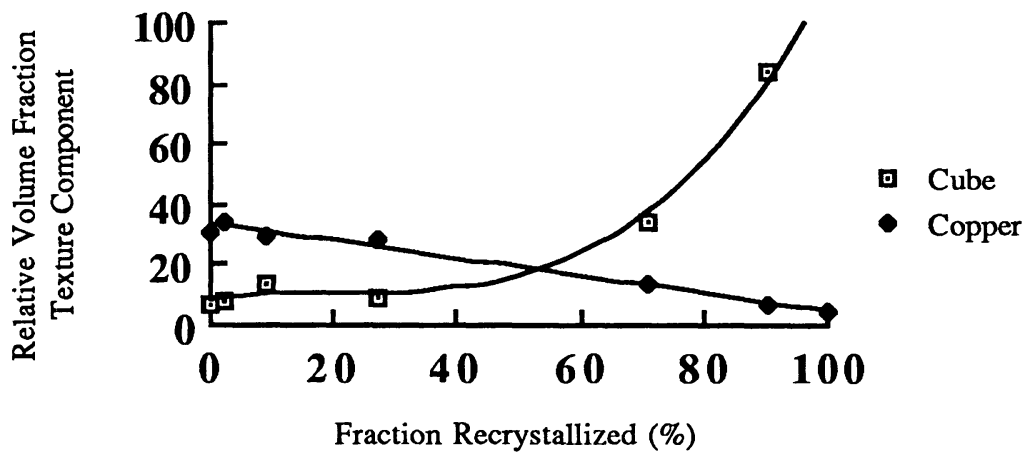

Figure 2. Cube vs. Copper Texture Component Comparison, 90\% Cold Rolled 


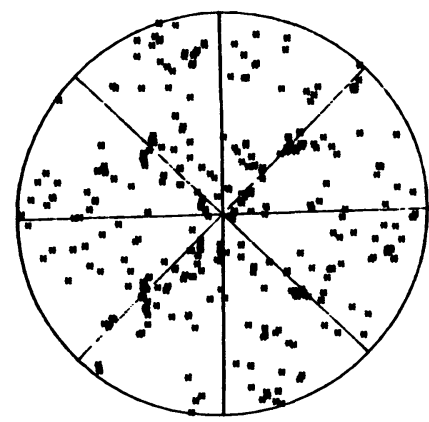

a)

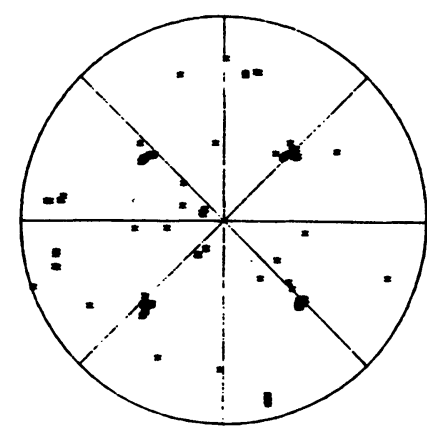

b)

Figure 3. EBSP Data on (111\} Pole Figures a) $73 \%$ rolled and b) $90 \%$ rolled; compare with Fig. 1b and 1c, respectively.

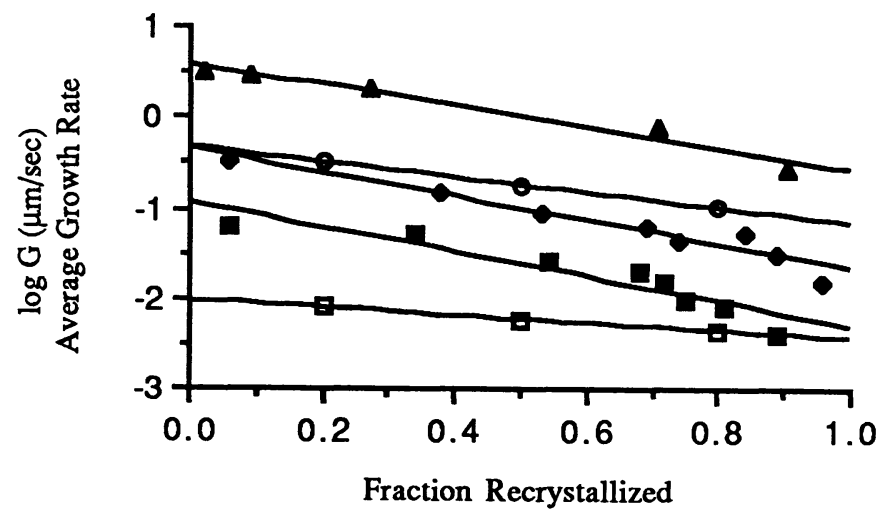

- $58 \%$ Rolled

- $73 \%$ Rolled

- $90 \%$ Rolled

- Ryde et al. Fine Grain Data

- Ryde et al. Coarse Grain Data

Figure 4. Average Growth Rate of Cold Rolled Copper, Annealed at 225C

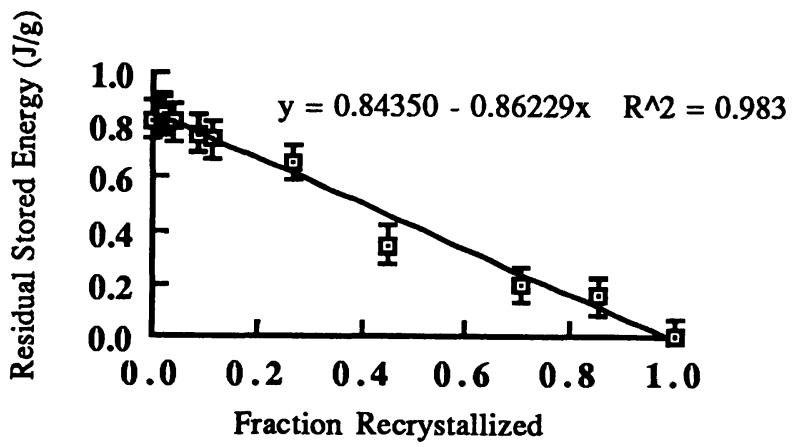

Figure 5. 90\% Cold Rolled Copper Residual Stored Energy Measurement 